\title{
A Probabilistic Study of Ground Motion Simulation for Bangkok soil
}

\section{Nilupa Herath, Priyan Mendis, Lihai Zhang}

Department of Infrastructure Engineering

University of Melbourne

VIC 3010

Australia

Corresponding Author: nherath@unimelb.edu.au

\begin{abstract}
Due to the soft soil condition, it has been found that buildings in Bangkok locating $200 \mathrm{~km}$ away from epicentral of an earthquake can be damaged as a result of high ground motion (e.g. earthquakes of magnitudes 5.3-5.9 in 1983). Because of rapid urban expansion and population growth in cities with soft soil condition, such as Bangkok, the assessment of seismic vulnerability of building structures becomes necessary. The purpose of this study is to quantify variability and develop attenuation and amplification models of ground motions for Bangkok sites. First, by analysing soil profile of Bangkok using Latin Hypercube sampling technique, critical attenuation and amplification characteristics, such as peak ground acceleration, ground motion intensity, frequency content and significant ground duration, were obtained. Then, the statistical information on the attenuation and amplification models of these characteristics was established and used to conduct a series of non-linear seismic analysis of a typical four story commercial building in Bangkok. The research outcomes demonstrate that the developed models are capable of predicting the damage indices of buildings in Bangkok under different earthquake intensities and epicentral distances.
\end{abstract}

Key words: Latin Hypercube sampling, Attenuation and amplification models, soft soil, Bangkok seismicity

\section{Introduction}

Thailand is located in the Eurasian plate which is close to the Andaman-Sumatra-Myanmar plate boundary. In 1983, a number of moderate earthquakes of magnitude 5.3-5.9 struck the western province of Thailand. The epicentral distances of the previous earthquakes that occurred along this plate boundary are approximately 400-800 km from Thailand (Samuthsakorn 1983). The joint 
research work of the Department of Mineral Resources (Thailand), Chulalongkorn University (Thailand) and Akita University (Japan) provided a significant contribution to the understanding of the potential active faults in Thailand (Hinthong 1995; Kosuwan et al. 1999). Fenton et al, (2003) identified a few active faults by carrying out paleoseismic investigations in Northern and Western Thailand. By studying seismicity around and within Thailand, Warnitchai and Lisantono (1996) suggested an attenuation relationship. Based on 21 zones identified by Charusiri et al. (2004), Palasri (2006) developed a new probabilistic-based seismic hazard map for Thailand by implementing the strong ground motion attenuation model of Petersen et al. (2004). Using a new probabilistic approach, Frankel (1995) developed a seismic hazard map for Thailand representing crustal fault and subduction zone models, while Ornthammarath et al (2011) developed a new set of probabilistic seismic hazard maps based on latest US National Seismic Hazard Maps. These methods strongly depend on equality of the earthquake catalogue and smoothing parameters. Since information on the available earthquakes catalogue for Thailand is not very well established and development of attenuation and amplification models is an alternative method to derive the effect of seismicity in the particular site, this study utilizes the derivation of attenuation models for soft soil conditions in Bangkok, Thailand.

The seismic vulnerability and reliability assessment of structures normally begin with defining seismicity and hazard potential around the site of interest. Gutenburg and Richter's empirical formula (Gutenberg and Richter 1956) is often used to study seismicity around the area of interest. Earthquake magnitudes can be transferred to peak ground acceleration by an attenuation model appropriate for site conditions. While strong ground motion attenuation models were developed by Petersen et al (2004) for subduction zone earthquakes, model developed by Sadigh et al (1997) could be used for shallow crust earthquakes. With consideration of the variability of the probability distribution of peak ground accelerations, a number of attenuation models have been developed empirically based on statistical regression analyses of earthquake ground motions (Lai 1982, Petersen et al 2004, Sadigh et al 1997). However, most of these studies are only applicable for stiff ground sites and on rock sites due to the availability of historical earthquake data (Dobry et al. 1978; Lai 1982; Seed et al. 1976; Tso et al. 1992; Vanmarcke and Lai 1980). For the soft soil conditions such as Bangkok, the development of adequate attenuation models becomes necessary. The study of Nutalaya and Shrestha (1990) showed that Estava model (Esteva and Villaverde 1973) may be one of the applicable attenuation models to overcome the model limitation. However further development work is still required in order to correctly simulate the soft soil conditions in Bangkok, Thailand. Therefore this study focus on developing attenuation and amplification models for these types soft soil conditions in Bangkok. 


\section{Methodology}

Earthquake ground motions are normally not readily available at the site of interest. Two approaches are available to quantify the earthquake ground motions and its inherent variability. One is to study the fault rupture, energy release mechanism, wave travel-path geology and local site conditions. The second approach is to investigate historical earthquake ground motions and establish the relationship between earthquake magnitudes, distances and the governing parameters of earthquake records. Since the information regarding the geological structures is not precisely known in Thailand, the variabilities of the parameters are quantified by statistical analysis of the historical earthquake records.

The procedure adopted in this study is summarised as follows.

- Selection of a potential earthquake magnitude (M) and epicentral distance (R)

- Establishment of attenuation or amplification models of peak ground acceleration $\left(a_{D}\right)$, ground motion intensity $\left(\mathrm{I}_{0}\right)$, significant ground motion duration $\left(\mathrm{S}_{0}\right)$, damping coefficient $\left(\zeta_{\mathrm{g}}\right)$ and predominant frequency $\left(\mathrm{f}_{\mathrm{g}}\right)$.

- Quantifying the variability associated with the attenuation and amplification models of the parameters $\mathrm{a}_{\mathrm{D}}, \mathrm{I}_{0}, \mathrm{~S}_{0}, \zeta_{\mathrm{g}}$, and $\mathrm{f}_{\mathrm{g}}$.

- Sampling representative values from the variability and match the sampled data by the Latin Hypercube sampling technique.

- Simulating a series of earthquake ground motions representing variability of earthquake ground motions.

- Conducting a case study for a typical 4 storey commercial frame building in Bangkok using the developed attenuation and amplification models.

For the sensitivity analysis of this study, the epicentral distances of 50, 100 and $150 \mathrm{~km}$ from Bangkok were considered. The magnitudes of $\mathrm{M}=5.5$ and $\mathrm{M}=6.0$ are likely to occur in the small faults to the west of Bangkok and $M=6.5$ is chosen for assessing the extreme condition. Table1 shows the different combination of magnitude and epicentral distances used for investigation in this study.

Table 1: Earthquake magnitudes and epicentral distance for sensitivity analysis

\begin{tabular}{ccccc}
\hline $\mathbf{M}$ & Return Period (years) & \multicolumn{3}{c}{ Sources to Bangkok (R, kilometers) } \\
\hline $\mathbf{5 . 5}$ & 67.7 & 50 & 100 & 150 \\
$\mathbf{6 . 0}$ & 334.3 & 50 & 100 & 150 \\
$\mathbf{6 . 5}$ & 2636.5 & 50 & 100 & 150 \\
\hline
\end{tabular}


Although many attenuation and amplification models of ground motions have been proposed in the past (Warnitchai and Lisantono, 1996, Sadigh, 1997), the information on attenuation and amplification model errors is not readily available. In this study, the errors of attenuation and amplification models were expressed in terms of error coefficients. To include the variability of earthquake ground motions in attenuation and amplification models, the error coefficients were expressed in terms of the statistical means, standard deviations, coefficients of variation and probability distributions.

Attenuation and amplification models for stiff ground and rock sites are developed first and then are modified for soft soil sites as Bangkok which is located on soft soil. One of the most important parameters in modeling earthquake ground motions in a stochastic process is the standard deviation $(\sigma)$ of the amplitudes or the variance value $\left(\sigma^{2}\right)$. In this study, the variability of $\sigma^{2}$ values are modeled to make the variability of the ground motion intensity consistent with the variability observed from actual earthquakes.

To study seismic risk in Bangkok, the amplification of ground motion intensity due to soft soil was accounted for. The soil underlying Bangkok and its vicinity area is classified as soft soil types. In this study, the soft soil is assumed to be excited by underneath rock motions and shear waves propagating towards top soil. The variability of rock motions developed in this study is assigned as the variability of rock motions. Three different soil profiles (typical profile is shown in Figure 1) are selected to represent the variability of soil deposits in Bangkok. The response motions are analysed in order to establish attenuation models of peak ground acceleration, the $90 \%$ ground motion intensity, significant ground motion duration and frequency content of ground motions for Bangkok sites. The variabilities of attenuation and amplification models were statistically quantified. Seismic response of soil was determined mainly by shear modulus and damping characteristics. Some available characteristics for clay soil were used in this study to perform the seismic analysis of soft soils in Bangkok.

The computer programme SHAKE was employed to perform the soil response analyses (Schnabel et al. 1972). The program is based on one dimensional wave propagation theory. It considers the vertical propagation of shear waves through linear viscous elastic system. The system consists of ' $N$ ' horizontal layers which extend to infinity in the horizontal direction and has a half space as the bottom layer. Each layer is assumed to be homogeneous and isotropic and is characterized by the thickness, mass density, shear modulus and damping coefficient. The non-linearity of shear modulus and damping were accounted for by using an iterative procedure to obtain the values of shear modulus and damping compatible with the effective shear strains in each layer.

The soil profile in Bangkok can be described as follows. 
1. Weathered zone of dark grey clay which forms an apparently hard crust to a depth of about $4.5 \mathrm{~m}$.

2. Soft, highly compressible, dark grey clay beneath the weathered zone to a depth of about 10 m.

3. Stiff clay, often fissured, light grey and brown in colour, to approximately depth of $15 \mathrm{~m}$. Sand and gravel beds, with some sandy clay, which occur alternatively to an indeterminate depth at least $300 \mathrm{~m}$.

General soil properties obtained from samples taken from the depth of $6 \mathrm{~m}$ to $8 \mathrm{~m}$ are given in Table 2 .

Table 2: Properties of Bangkok soft clay

\begin{tabular}{|l|c|}
\hline \multicolumn{1}{|c|}{ Properties } & Quantity \\
\hline Natural water content & $119-131 \%$ \\
\hline Natural void ratio & $3.46-3.60$ \\
\hline Degree of saturation & $96-100 \%$ \\
\hline Grain size distribution & $1-9 \%$ \\
\hline Sand & $26-32 \%$ \\
\hline Silt & $64-72 \%$ \\
\hline Clay & $2.65-2.765$ \\
\hline Specific gravity & $111-125 \%$ \\
\hline Liquid limit & $42-50 \%$ \\
\hline Plastic limit & $69-75$ \\
\hline Activity number & $0.96-1.08$ \\
\hline Liquid index & Greenish grey \\
\hline Colour & $13.1-15.2$ gm/litre \\
\hline Soluble salt content & $3.30-3.55 \%$ \\
\hline Organic matter & $8.6-8.8$ \\
\hline pH & \\
\hline
\end{tabular}

The variability of soil profiles considerably affects the variability of soil response. Three soil profiles were initially investigated by exciting by a rock motion of the 1985 Mexico earthquake. The response spectra of the three response motions indicate that soil response is not affected if soil profiles are not significantly different. This characteristic has also been reported by Arango Ad Dietrich (1972). A typical soil profile for Bangkok used in this study is shown in Figure 1. 


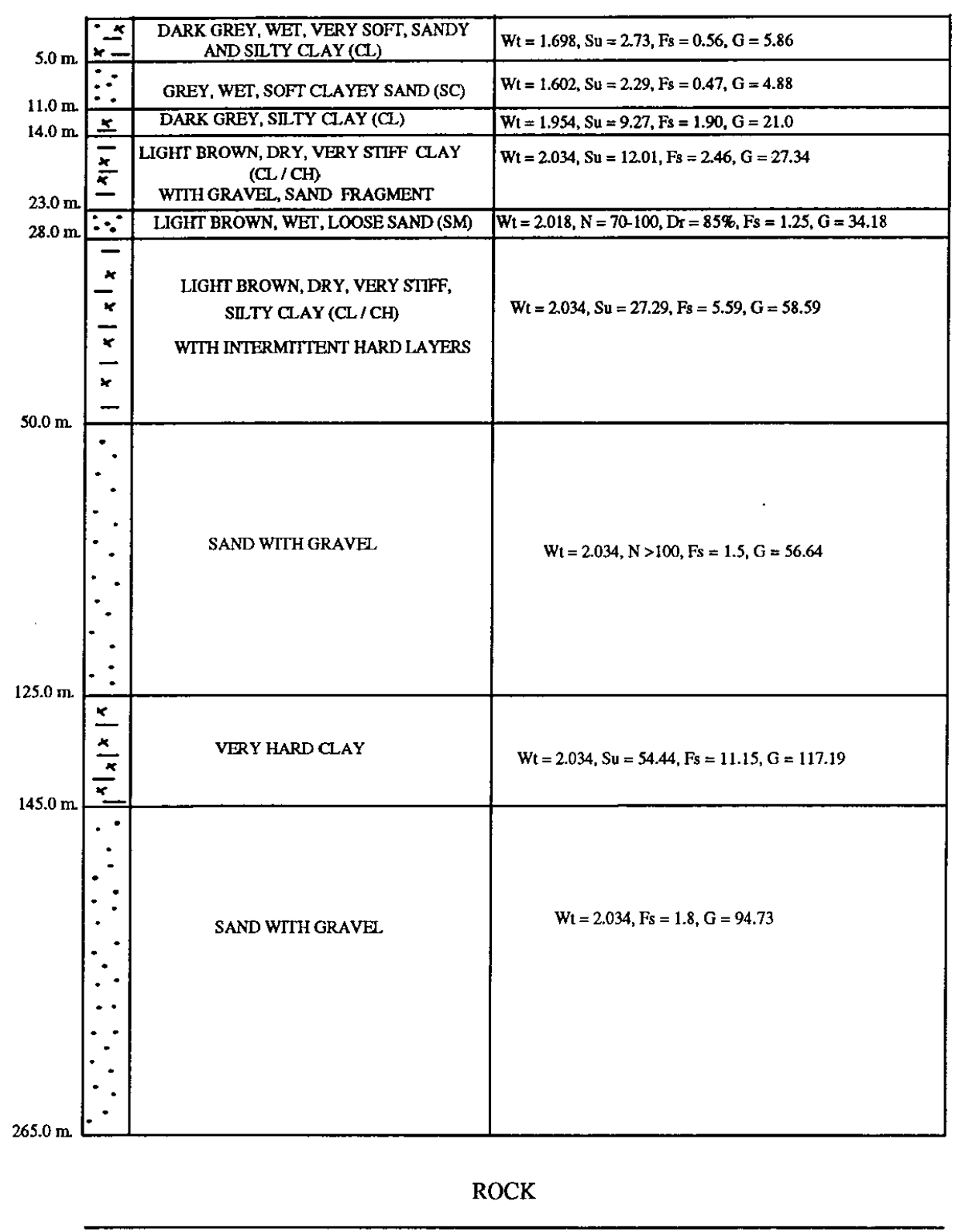

$W t .\left(t / m^{3}\right), S u\left(t / m^{2}\right), G\left(t / m^{2} \cdot 1000\right)$

Figure 1: Bangkok soil profile

\subsection{Latin Hypercube sampling (LHS)}

One of the major problems in the analysis of complex models arises from the uncertainties and the complexity of the input variables. Uncertainties exist as most of the input is based on statistical data. In addition, the complexity of the modeling makes the relationships among the input variables not mathematically tractable. Therefore, it is desirable to perform sensitivity studies of the input-output relationships. The variability of input variables can be sampled by a sampling technique.

Latin Hypercube sampling was developed by McKay et al. (1979) and originally designed for use within the sensitivity analysis of computer simulations. As this method of sampling requires only a 
small number of input samples to run, this is a practical benefit. The LHS method is described below for " $k$ " input variables that are of interest and " $N$ " samples that are required.

Each input variable ' $\mathrm{X}$ ' gives a probability density function $\mathrm{f}(\mathrm{x})$ and domain $\left[\mathrm{x}_{\min }, \mathrm{x}_{\max }\right]$. This domain is divided into $\mathrm{N}$ equal disjoint intervals, each of ones with its own minimum ' $\mathrm{x}_{\min }$ and maximum, $\mathrm{x}_{\max }$. Thus,

$\frac{1}{N}=\int_{x_{i} \min }^{x_{i} \max } f(x) d x, \quad \forall \in\{1,2, \ldots ., N\}$

' $\mathrm{x}_{\mathrm{i}, \min }$ ' and ' $\mathrm{x}_{\mathrm{i}, \max }$ ' are iteratively determined if

$x_{i, \min }=\inf (x: \quad F(x)>0$

$x_{i, \max }=F^{-1}\left(F\left(x_{i, \text { min }}+\frac{1}{N}\right), \quad \forall \mathrm{i} \in\{1,2, \ldots \mathrm{N}\}\right.$

$x_{i+1, \min }=x_{i, \max }, \quad \forall \mathrm{i} \in\{1,2, \ldots . \mathrm{N}-1\}$

As cumulative distribution functions are used in this iteration, it only needs to be slightly adapted for use with discrete variables. Given any ' $i$ ' a new random variable can be determined ' $x_{i}$ ' with a probability density function (PDF) of:

$$
f_{i}(x)=\left[\begin{array}{cc}
N . f(x) & \text { if } \mathrm{x} \in\left[\mathrm{x}_{\mathrm{i}, \min }, \mathrm{x}_{\mathrm{i}, \max }\right] \\
0 & \text { Otherwise }
\end{array}\right]
$$

This is a probability function

$$
\int f_{i}(x) d x=1
$$

A single sample ' $\mathrm{x}_{\mathrm{i}}$ ' for each input variable $(\mathrm{X})$ is taken from each of the ' $\mathrm{N}$ ' new random variables $\left(\mathrm{x}_{\mathrm{i}}\right)$.

Monte Carlo and Latin Hypercube sampling techniques were conducted to compare the results for error coefficient of peak ground acceleration with 10, 25, 50 and 1000 sampling sizes. Error coefficient with samples of 50 is shown in Figure 2. It is clear from the figure that better results are predicted from Latin Hypercube sampling with lesser samples compared to Monte Carlo sampling technique. 


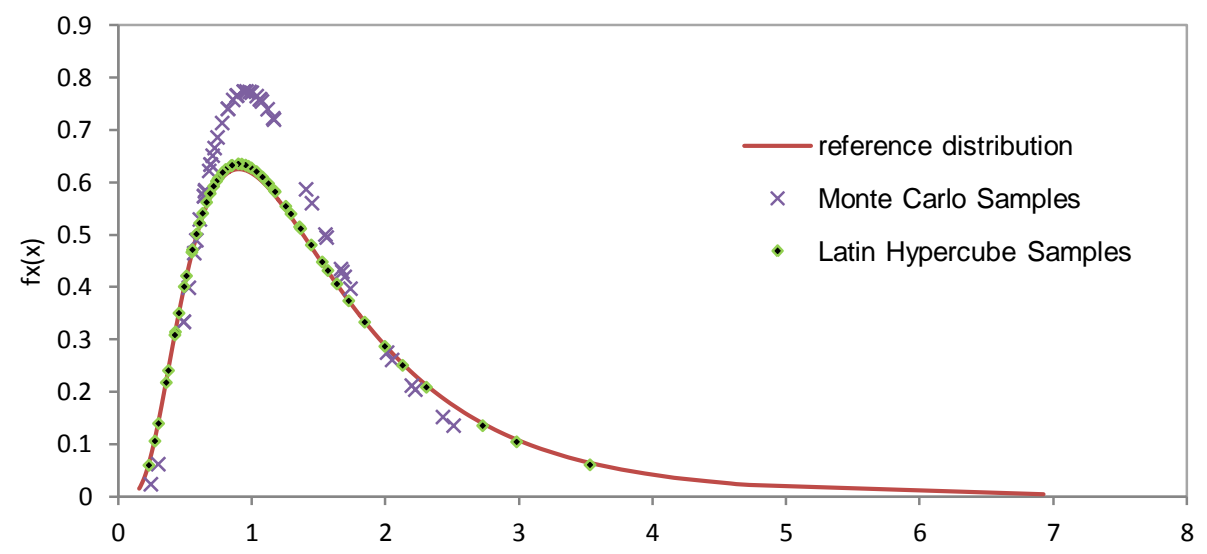

Figure 2: Comparison of Monte Carlo sampling and Latin Hypercube sampling with 50 intervals for error coefficient of peak ground acceleration

\section{Results and discussion}

\subsection{Characteristics of attenuation and amplification models for rock sites and stiff ground sites}

\subsubsection{Peak ground acceleration}

Attenuation models of peak ground accelerations have already been developed by many researchers. Most of the attenuation models provide maximum acceleration at ground surface. These models incorporate the effect of local soil conditions. Seed and Idriss's (1969) attenuation model provides peak ground accelerations at rock sites. Esteva and Villaverde's model (1977) fits the data recorded on soil reasonably well. These peak ground acceleration data for stiff soil sites have been obtained from the data available in Seed et al. (1976), Dobry et al. (1978), Vanmarcke and Lai (1980), and Tso et al. (1992). Seed and Idriss (1969) attenuation model was used to fit the peak acceleration data recorded on rock sites and it was observed from this study that attenuation model provides lower values than recorded values. Hence the model was modified accordingly as shown below.

For rock sites

$\mathrm{a}_{\mathrm{D}}=0.112 \cdot \exp ^{0.9 \mathrm{M}} \cdot \mathrm{R}^{-1.6} \cdot \mathrm{C}_{a}$

$\operatorname{Ln}\left(C_{a}\right)=N(-0.09,0.63)$ and $\operatorname{Cov}\left(C_{a}\right)=0.69$

For stiff ground sites

$\mathrm{a}_{\mathrm{D}}=5.6 \cdot \exp ^{0.8 \mathrm{M}} \cdot(\mathrm{R}+40)^{-2} \cdot \mathrm{C}_{a}$

$\operatorname{Ln}\left(\mathrm{C}_{\mathrm{a}}\right)=\mathrm{N}(0.0,0.50)$ and $\operatorname{Cov}\left(\mathrm{C}_{\mathrm{a}}\right)=0.53$

Where $\mathrm{M}$ is the Richter magnitude, $\mathrm{R}$ is epicentral distance and $\mathrm{C}_{\mathrm{a}}$ is error of coefficient. 
It was observed that error coefficient $\mathrm{C}_{\mathrm{a}}$ and the error coefficient $\mathrm{C}_{\mathrm{a}}$ of maximum accelerations recorded on rock sites is log-normally distributed. Figure 3 depicts the cumulative probability distribution of the error coefficient of the peak acceleration on rock sites.

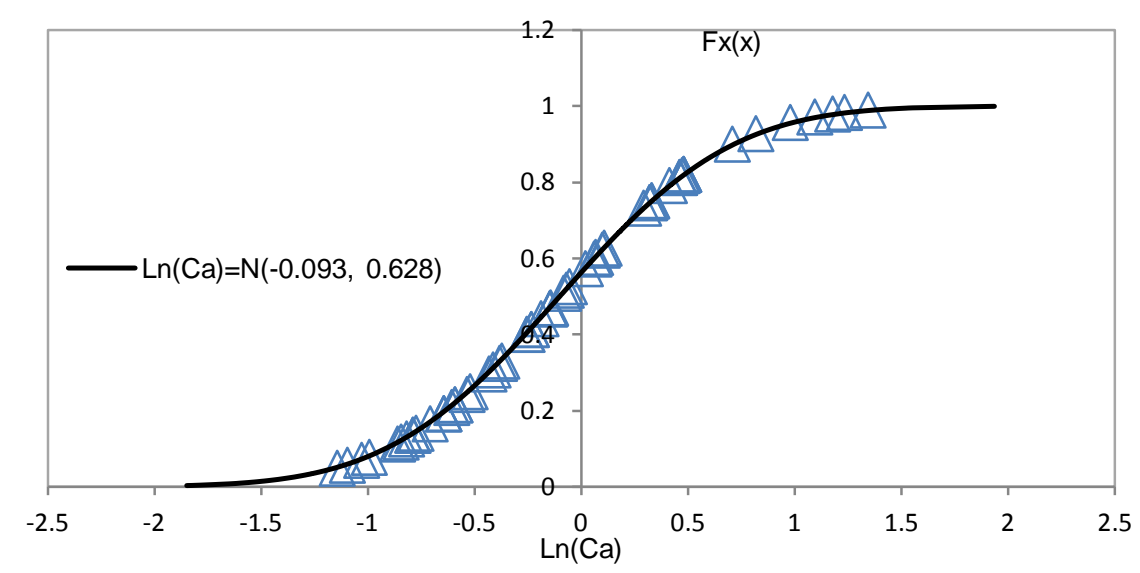

Figure 3: The cumulative probability distribution of the error coefficient of the peak acceleration on rock sites

\subsubsection{0\% ground motion intensity}

Vanmarcke and Lai (1980) studied the total ground motion intensity, $\mathrm{I}_{\mathrm{E}}$, of 140 earthquakes recorded on rock and stiff firm ground sites. The total ground motion intensity reported by Vanmarcke and Lai (1980) was used in this study. Figure 4 shows plots of $I_{0}$ for rock sites for $M=5$ to 6 . The attenuation formula suggested by Kumamura and Galambos (1989) for $\mathrm{I}_{\mathrm{E}}$ was modified to fit the $\mathrm{I}_{\mathrm{o}}$ data and the modified formula is given in Equations 9 and 10. The probability distribution of the error coefficient $\mathrm{C}_{\mathrm{I}}$ is obtained by the statistical analysis of the residuals from the model. The probability distribution of the error coefficient is tested by the Kolmogorov-Smirnov (K-S) method (Ang and Tang 1975). The error coefficient $\left(\mathrm{C}_{\mathrm{I}}\right)$ of the $90 \%$ ground motion intensity $\mathrm{I}_{\mathrm{o}}$ for stiff soil sites and rock sites are shown to be log-normally distributed.

For rock sites

$\mathrm{I}_{o}=5.3 \cdot 10^{-6} \cdot \exp ^{2.14 \mathrm{M}} \cdot \mathrm{R}^{-1.95} \cdot \mathrm{C}_{\mathrm{I}}$

$\operatorname{Ln}\left(C_{I}\right)=N(-0.0,0.85)$ and $\operatorname{Cov}\left(C_{I}\right)=1.03$

$\underline{\text { For stiff ground sites }}$

$\mathrm{I}_{o}=5 \cdot 10^{-5} \cdot \exp ^{2.6 \mathrm{M}} \cdot \mathrm{R}^{-3} \cdot \mathrm{C}_{\mathrm{I}}$ 
$\operatorname{Ln}\left(\mathrm{C}_{\mathrm{I}}\right)=\mathrm{N}(-0.47,1.73)$ and $\operatorname{Cov}\left(\mathrm{C}_{\mathrm{I}}\right)=1.35$

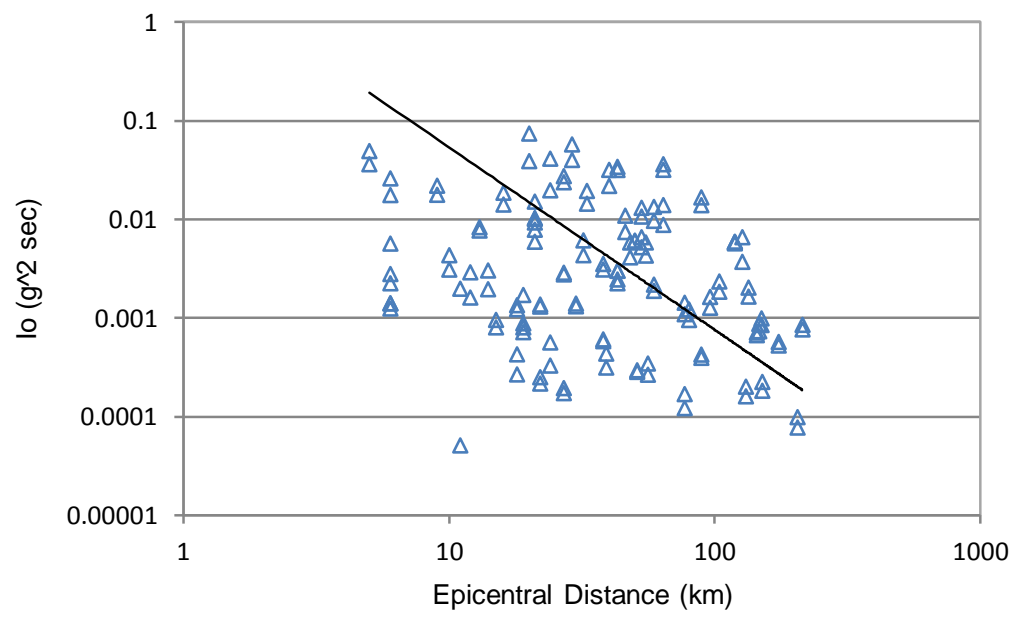

Figure 4: Attenuation of the $90 \%$ ground motion intensity, Io, for rock sites

\subsubsection{Significant ground Motion Duration, $S_{0}$}

The significant ground motion duration data were employed to develop $S_{o}$ models and quantify the model variability. Equation 11 and 12 were derived to fit $S_{o}$ data for rock sites and stiff firm ground respectively.

For rock sites

$S_{0}=\left(0.0005 \exp ^{1.0 M}+0.08 R\right) \cdot C s$

$\operatorname{Ln}(\mathrm{Cs})=\mathrm{N}(0.6,0.707)$ and $\operatorname{Cov}(\mathrm{Cs})=0.818$

For stiff ground sites

$S_{0}=\left(0.007 \exp ^{1.0 M}+0.15 R\right) \cdot C s$

$\operatorname{Ln}(\mathrm{Cs})=\mathrm{N}(-0.3,0.83)$ and $\operatorname{Cov}(\mathrm{Cs})=0.9531$

Where Cs is error coefficient for significant ground motion duration, $S_{o}$

It was noted that the significant ground motion duration increases when epicentral distance increases. Significant ground motion duration of recorded earthquakes on soil for $5.0<\mathrm{M}<7$ and curve plotted with modified equation for rock sites are shown in Figure 5 and cumulative probability distribution of the error coefficient of significant duration for rock sites is shown in Figure 6 respectively. 


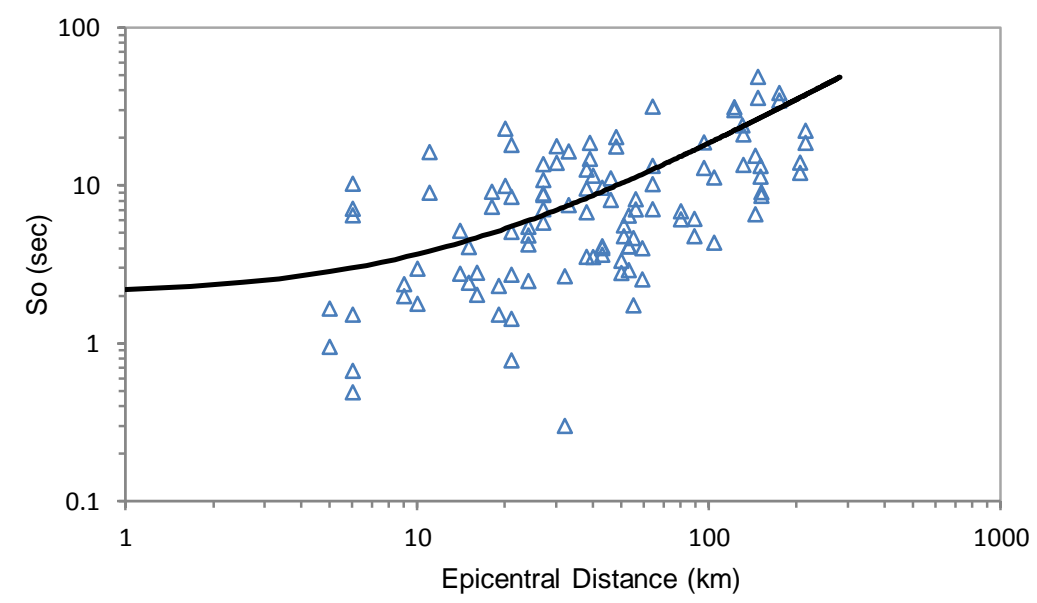

Figure 5: Significant ground motion duration of recorded earthquakes on soil for $5.0<\mathrm{M}<7$

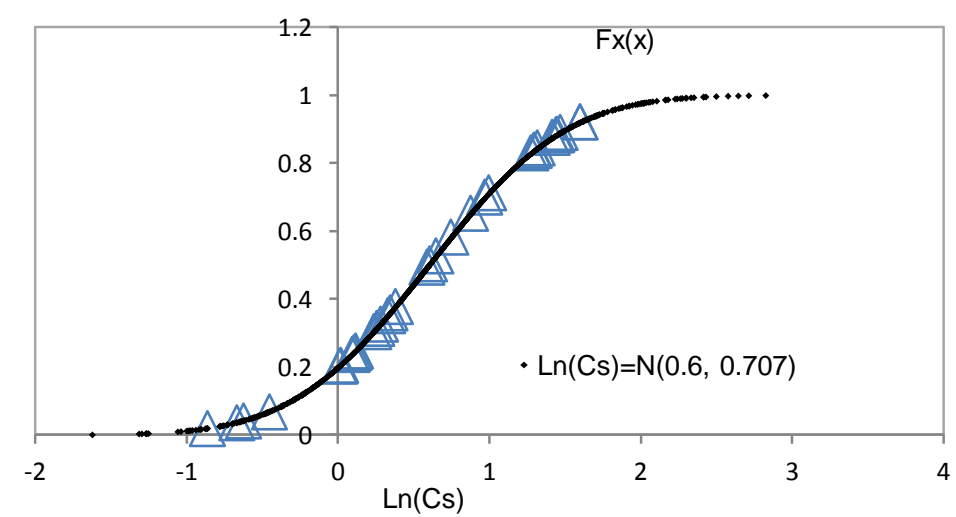

Figure 6: The cumulative probability distribution of the error coefficient of $S_{\mathrm{o}}$ for rock sites

\subsubsection{Frequency Content in Earthquake Motions}

To model frequency content of an earthquake ground motion, Kanai-Tajimi's (KTJ) power spectral density function is the most commonly used among the available power spectral density (PSD) functions. The parameters required in the PSD are the predominant frequency, $\omega_{\mathrm{g}}$ and the damping coefficient, $\xi_{g}$. Although this model was used by many researchers and because Kanai-Tajimi's power spectral density function is not consistent with power spectra of actual earthquake motions, Clough and Penzien (1993) suggested that the KTJ power spectral function should be filtered with an appropriate transfer function. In this study, modified KTJ power spectral function was utilised to make it consistent with observed earthquake power spectra.

To model the frequency spectra of earthquake motions, twenty earthquakes recorded on different sites as shown in Table 3 were synthesized through a Fast Fourier Transform (FFT) procedure. 
Table 3: Earthquake records for frequency spectral analysis

\begin{tabular}{|c|c|c|c|c|c|}
\hline Earthquake Location & $\begin{array}{l}\text { Site } \\
\text { Condition }\end{array}$ & $\begin{array}{l}\text { Distance } \\
(\mathrm{km})\end{array}$ & $\begin{array}{r}\mathbf{f}_{\mathbf{g}} \\
\mathrm{Hz}\end{array}$ & $\begin{array}{c}\boldsymbol{\omega}_{\mathbf{g}} \\
\mathrm{Rad} / \mathrm{sec}\end{array}$ & $\xi_{\mathrm{g}}$ \\
\hline 1. Cape Mendocio, US, 1975 (VH01) & Rock & 30 & 6.2 & 39 & 0.15 \\
\hline 2. Honshu, Japan, 1968 (VH03) & Rock & 81 & 6.0 & 33 & 0.2 \\
\hline 3. Honshu, Japan, 1968 (VH04) & Stiff & 81 & 5.6 & 31 & 0.3 \\
\hline 4. Honshu, Japan, 1968 (HI15) & Rock & 116 & 4.0 & 38 & 0.8 \\
\hline 5. Honshu, Japan, 1978 (LO03) & Stiff & 112 & 0.80 & 5 & 0.79 \\
\hline 6. Lae, 1971 (LEA.5A) & Incomplete & Unknown & 4.8 & 32 & 0.43 \\
\hline 7. Mexico, 1985 (SCT1.NS) & Rock & 415 & 0.7 & 4 & 0.4 \\
\hline 8. Musa, 1972 (MUSA.1B) & Rock & Unknown & 3.63 & 23 & 0.21 \\
\hline 9. New Zealand, 1968 (NZQ 02T) & Stiff & Unknown & 4.5 & 10 & 0.45 \\
\hline 10. New Zealand, 1973 (NZQ 10T) & Stiff & Unknown & 2.3 & 12 & 0.8 \\
\hline 11. New Zealand, 1977 (NZQ 20T) & Rock & Unknown & 2.0 & 25 & 0.6 \\
\hline 12. San Fernando, 1971 (Q53) & Incomplete & Unknown & 2.8 & 17 & 0.6 \\
\hline 13. Tangshan, China, 1976 (VL02) & Stiff & 172 & 1.8 & 5 & 0.6 \\
\hline 14. Tangshan, China, 1976 (VL04) & Rock & 373 & 1.0 & 10 & 0.62 \\
\hline 15. Tangshan, China, 1976 (VL08) & Stiff & 122 & 1.2 & 3 & 0.8 \\
\hline 16. Yonki, 1968 (YONKI.3A) & Incomplete & Unknown & 5.1 & 27 & 0.4 \\
\hline 17. Yonki, 1969 (YONKI.6A) & Incomplete & Unknown & 4.61 & 29 & 0.3 \\
\hline 18. Yonki, 1969 (YONKI.7A) & Incomplete & Unknown & 4.93 & 33 & 0.3 \\
\hline 19. Yonki, 1970 (YONKI.8A) & Incomplete & Unknown & 4.29 & 31 & 0.3 \\
\hline 20. Kobe, 1995 (FUK000) & Stiff & 157.2 & 0.9 & 31 & 0.6 \\
\hline
\end{tabular}

The Kanai-Tajimi power spectral density function was modified and the values of the parameters, predominant frequency and damping coefficient were selected by trial and error to fit the modified power spectrum to the normalized power spectrum. The modified Kanai-Tajimi power spectral density function is given in Equation13.

$\mathrm{S}(\mathrm{f})=\mathrm{C}\left[\frac{0.05+4 \xi_{\mathrm{g}}^{2}\left(\mathrm{f} / \mathrm{fg}_{\mathrm{g}}\right)^{2}}{\left[1-\left(\mathrm{f} / \mathrm{f}_{\mathrm{g}}\right)^{2}\right]+4 \xi_{\mathrm{g}}^{2}\left(\mathrm{f} / \mathrm{f}_{\mathrm{g}}\right)^{2}}\right]$

Where $\mathrm{C}$ is a constant, $\mathrm{f}_{\mathrm{g}}$ is the predominant frequency and $\xi_{\mathrm{g}}$ is the damping coefficient. 
Through critically analysing the above mentioned 20 earthquake records given in Table 3, it was found that the value of damping coefficient and predominant frequency for Kanai-Tajimi's power spectral density function (KTJ) and modified Kanai-Tajimi's power spectral density function (MKTJ) power spectral density functions were practically the same. Normalised Kanai-Tajimi (KTJ) and Modified Kanai-Tajimi (MKTJ) power spectral density for Musa-1b earthquake record-1972 is shown in Figure 7 for clarity.

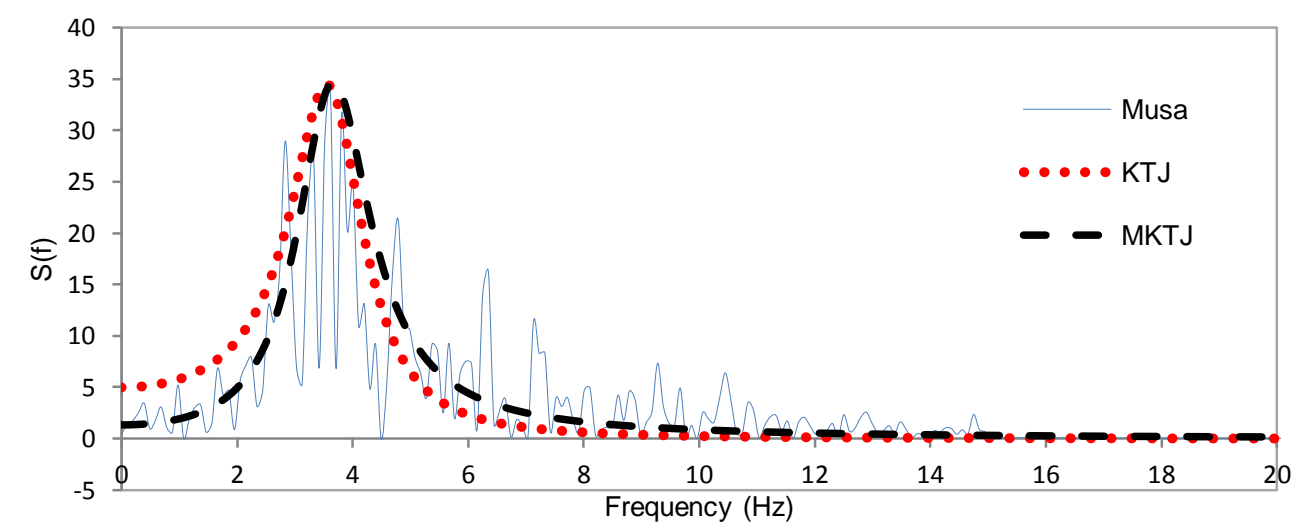

Figure 7: Normalised Kanai-Tajimi (KTJ) and Modified Kanai-Tajimi (MKTJ) power spectral density for Musa-1b earthquake record-1972

As observed from Table 3, the predominant frequencies of rock motions fall in between 20 to 40 rads/sec (or 3 to $7 \mathrm{~Hz}$ ). An exception is the Tangshan earthquake in China, which travelled a distance of $373 \mathrm{~km}$, containing a low predominant frequency of $10 \mathrm{rads} / \mathrm{sec}$ of $1.59 \mathrm{~Hz}$.

The average predominant frequency $\left(f_{g}\right)$ and damping coefficient $\left(\xi_{\mathrm{g}}\right)$ have been investigated from the data provided by Lai (1982) and shown in Table 4. It shows that the mean values of the predominant frequency and damping coefficient for stiff firm ground and rock sites are similar. The predominant frequency and frequency content are not affected by the two different site conditions. The values of $f_{g}$ and $\xi_{g}$ from both sites are combined to quantify the variabilities.

Table 4: Comparison of predominant frequency and damping coefficient of earthquake ground motions for stiff firm ground and rock sites

\begin{tabular}{lllll}
\hline & \multicolumn{2}{l}{ Predominant Frequency, $\mathbf{f}_{\mathbf{g}}(\mathbf{H z})$} & \multicolumn{2}{l}{ Damping Coefficient, $\boldsymbol{\zeta}_{\mathbf{g}}$} \\
\cline { 2 - 5 } & Mean & Cov & Mean & Cov \\
Stiff soil & 3.03 & 0.43 & 0.313 & 0.437 \\
Rock & 3.08 & 0.61 & 0.319 & 0.529 \\
\hline
\end{tabular}


Lai (1982) suggested a damping coefficient of 0.32 for all epicentral distances. It was observed that $\xi_{\mathrm{g}}$ increases when epicentral distance increases. Equation 14 gives the $\xi_{\mathrm{g}}$ as a function of the epicentral distance. The variability of damping coefficient is defined by an error coefficient, $\mathrm{C}_{\mathrm{d}}$. Figure 8 shows the cumulative distribution, statistical mean and standard deviation of the error coefficient $\left(\mathrm{C}_{\mathrm{d}}\right)$ which fitted by a log-normal distribution.

$\xi_{\mathrm{g}}=\exp ^{(-1.2+0.002 \mathrm{R})} \cdot C_{d}$

$\operatorname{Ln}(\mathrm{Cd})=\mathrm{N}(-0.132,0.40)$ and $\operatorname{Cov}\left(\mathrm{C}_{\mathrm{d}}\right)=0.42$

Where $\mathrm{R}$ is epicentral distance and $\mathrm{C}_{\mathrm{d}}$ is error coefficient of $\xi_{\mathrm{g}}$.

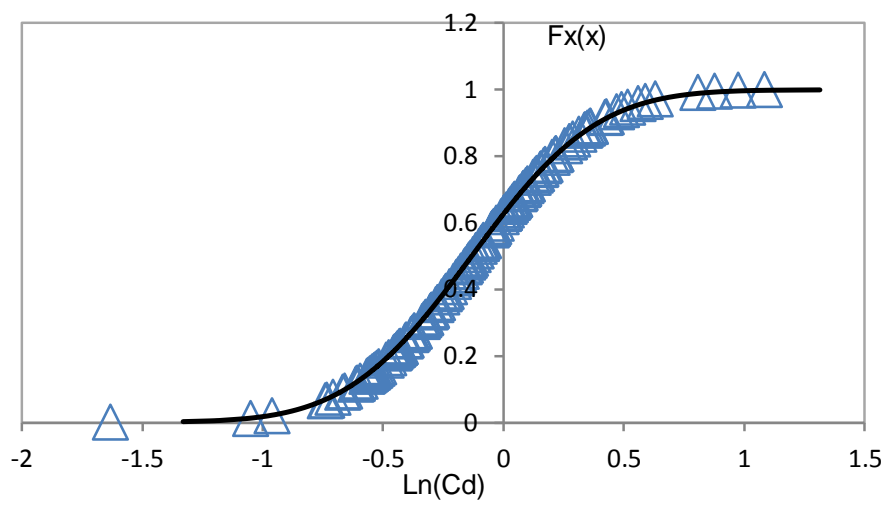

Figure 8: The cumulative probability distribution of the error coefficient of damping coefficient, $C_{d}$

Similarly, attenuation characteristics of predominant frequency were plotted and it was observed that the predominant frequency decreases when the epicentral distance increases. The error coefficient of the predominant frequency is shown to be log-normally distributed and following equation is derived from the data.

$\mathrm{f}_{\mathrm{g}}=\exp ^{(1.5-0.005 \mathrm{R})} \cdot \mathrm{C}_{f}$

$\operatorname{Ln}\left(\mathrm{C}_{\mathrm{f}}\right)=\mathrm{N}(-0.139,0.42)$ and $\operatorname{Cov}\left(\mathrm{C}_{\mathrm{f}}\right)=0.43$

Where $f_{g}$ is predominant frequency and $C_{f}$ is error coefficient of $f_{g}$.

\subsection{Characteristics of attenuation and amplification models for Bangkok soils}

The Bangkok soil consists of four layers as described above. The deepest zone (the 4th layer) mainly consists of gravel and sand, and so can be regarded as dense sand with gravels (AIT 1981). The wave velocity of this layer could be assumed to approach the wave velocity of rock-like materials. Based on 
this, shear velocity and shear modulus equation proposed by Seed and Idriss (1970) was used by Hwan (1985) to estimate the approximate rock depth. Hwan (1985) suggested the bed rock underneath the soft soil in Bangkok was approximately 300 meters.

Seismic response of soil is mainly determined by shear modulus and damping characteristics. Rock motions corresponding to different magnitudes and distances are simulated for the study of the statistical response of the Bangkok soft soil. Analysis of peak ground acceleration, the $90 \%$ ground motion intensity and significant ground motion duration of the response motions for Bangkok sites are described in detail in the following sections.

\subsubsection{Peak ground acceleration}

The variablities of the attenuation and amplification models of rock motions are expressed in terms of error coefficients as described in Section 3.1. The variability of each error coefficient is sampled using Latin Hypercube Sampling technique. In this study, the probability distributions of the error coefficients are divided into 32 equal probabilities (32 intervals for each input variable). The rock motions corresponding to the magnitudes and distances given in Table 1 are simulated for this study of the statistical response of the Bangkok soil.

The peak ground acceleration of the response motions were analysed and it was found that amplification factor increases when earthquake intensity of rock motion decreases. Figure 9 shows the amplification factor as a function of $\mathrm{M}$ and $\mathrm{R}$ at the epicentral distance of $50 \mathrm{~km}$ and earthquakes of magnitude $\mathrm{M}=5.5,6.0$ and $6.5 \mathrm{~m}$. The high level of intensity causes the soft clay to become highly non-linear. Due to this non-linear behaviour, the amplification factor is less than the factors for $\mathrm{R}=100$ and $150 \mathrm{~km}$ when the soft clay responses semi non-linearly or elastically. It can be concluded that for an earthquake originating at a larger distance from Bangkok, the intensity can become large, especially when the predominant frequency of rock motions coincides with the natural frequency of local soils. The results of this analysis cannot be verified due to lack of earthquake records in Bangkok. To improve the confidence in the results, the peak ground accelerations were compared with Esteva and Villaverde model (1977).

The modified attenuation model for ground motions at Bangkok sites is recommended in Equation 16 and graphically in Figure 10.

$$
\begin{aligned}
& a_{D}=0.112 \cdot \exp ^{0.9 M} \cdot R^{-1.6} F a_{D} \cdot C_{a} \\
& \operatorname{Ln}\left(\mathrm{C}_{\mathrm{a}}\right)=\mathrm{N}(0.0,0.48) \text { and } \operatorname{Cov}\left(\mathrm{C}_{\mathrm{a}}\right)=0.51
\end{aligned}
$$


Where $a_{D}$ is maximum acceleration of ground motion in Bangkok area $(\mathrm{g}), \mathrm{M}$ is Richter magnitude, $\mathrm{R}$ is epicentral distance, $F a_{D}$ is amplification factor of maximum acceleration given in Figure 9 and $C_{a}$ is error of coefficient.

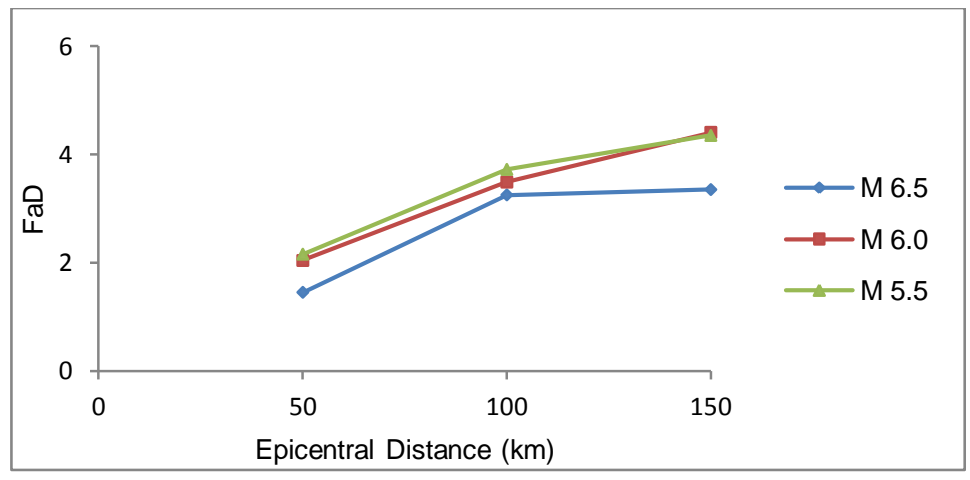

Figure 9: Amplification factor, $\mathrm{Fa}_{\mathrm{D}}$, for peak ground accelerations for Bangkok sites

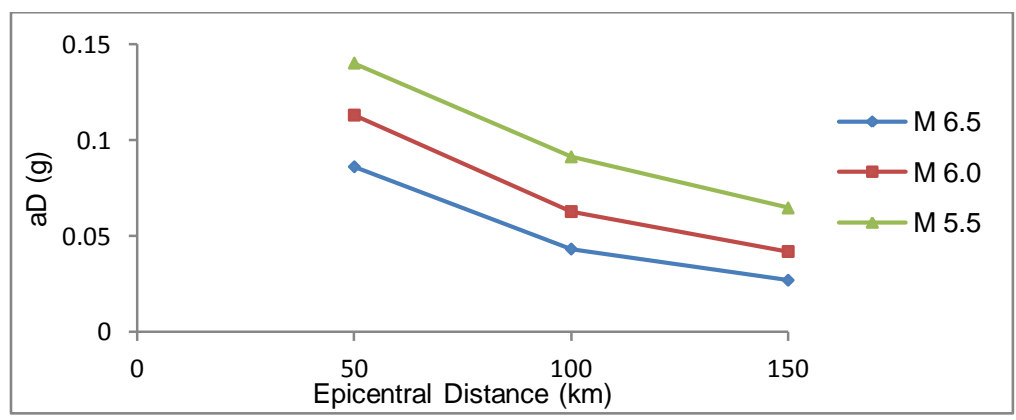

Figure 10: Attenuation of peak ground accelerations for Bangkok sites

\subsubsection{The 90\% ground motion intensity}

A complete analysis of $\mathrm{I}_{0}$, i.e. the integration of $5 \%$ to $95 \%$ squared accelerations of the response motions, was carried out. The amplification factor of $\mathrm{I}_{0}$ is found to decrease when earthquake intensity increases. This characteristic is similar to the amplification of $a_{D}$. An attenuation function of $I_{0}$ for Bangkok grounds is proposed in Equation 17. $\mathrm{I}_{0}$ is expressed as a function of $\mathrm{M}$ and $\mathrm{R}$. The variability of $I_{0}$ is accounted for by the error coefficient $C_{I}$. $C_{I}$ is obtained to be log normally distributed with a normal mean of -0.07 and a normal standard deviation of 0.93 . The Cov of $I_{0}$ for Bangkok is $113.59 \%$ of the Cov of $I_{0}$ of rock sites.

$\mathrm{I}_{o}=5.29 \cdot 10^{-6} \cdot \exp ^{2.14 \mathrm{M}} \cdot \mathrm{R}^{-1.95} \cdot \mathrm{C}_{\mathrm{I}}$

$\operatorname{Ln}\left(C_{I}\right)=N(-0.07,0.93)$ and $\operatorname{Cov}\left(C_{I}\right)=1.17$ 


\subsubsection{Significant ground motion duration}

The significant ground motion duration, $\mathrm{S}_{0}$, for each response motion was investigated. The overall significant ground motion results were statistically analysed. It was found that Bangkok soft clay amplifies the rock motion durations by $25 \%-50 \%$. The proposed $\mathrm{S}_{0}$ formulae for Bangkok sites are given in Equations 18 and 19.

$$
\begin{array}{ll}
\text { So }=\left(0.01 \cdot \exp ^{0.9 M}+0.07 R\right) \cdot C_{S} & \text { for } \mathrm{R}=50 \mathrm{~km} \\
\text { So }=\left(0.01 \cdot \exp ^{0.9 M}+0.08 R\right) \cdot C_{S} & \text { for } \mathrm{R}=100 \mathrm{~km} \text { and } 150 \mathrm{~km}
\end{array}
$$

\subsubsection{Frequency content}

A fast Fourier Transformation procedure is employed to investigate the frequency contents of the ground motions, resulting from seismic analyses of Bangkok soft soil. Thirty two motions for each pair of $\mathrm{M}$ and $\mathrm{R}$ were synthesised. The frequency content of the surface ground options for Bangkok sites was found to have two peaks of predominant frequencies. The first peak is approximately $0.5 \mathrm{~Hz}$ which is found to be the natural frequency of the soft soil. The second peak is the predominant frequency of the rock motion which depends on epicentral distance. It is observed that the tails of the frequency spectra decay as the epicentral distances increases.

An empirical power spectrum density function of earthquake ground motions for Bangkok sites is suggested in Equation 20and simulated earthquake plot is shown in Figure 11. The frequency content of ground motions for Bangkok sites can be modelled by this power spectral density function. A Matlab based program was developed based on this study to obtain ground motion records for Bangkok for soft soil sites, stiff firm ground and rock sites. Fourier spectrum and elastic response spectrum are shown in Figure 12.

$S(f)=C_{G}\left[\frac{0.005+4 \varepsilon^{2}\left(\frac{f}{f_{g}}\right)^{2}}{\left[1-\left(\frac{f}{f_{g}}\right)^{2}\right]^{2}+4 \varepsilon^{2}\left(\frac{f}{f_{g}}\right)^{2}}\right]+0.8\left[\frac{0.005+1.44\left(\frac{f}{0.5}\right)^{2}}{\left[1-\left(\frac{f}{0.5}\right)^{2}\right]^{2}+1.44\left(\frac{f}{0.5}\right)^{2}}\right]$

Where, $\varepsilon$ is dumping coefficient, $f_{g}$ is predominant frequency $(\mathrm{Hz})$ and $C_{G}$ is an arbitrary constant. 


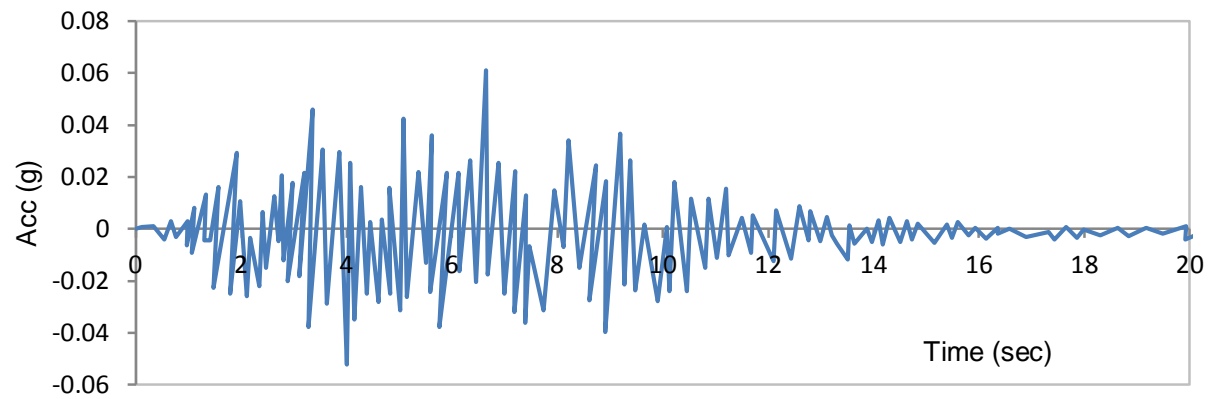

Figure 11: Simulated earthquake ground motion for Bangkok sites, $M=5.5, R=50 \mathrm{~km}$
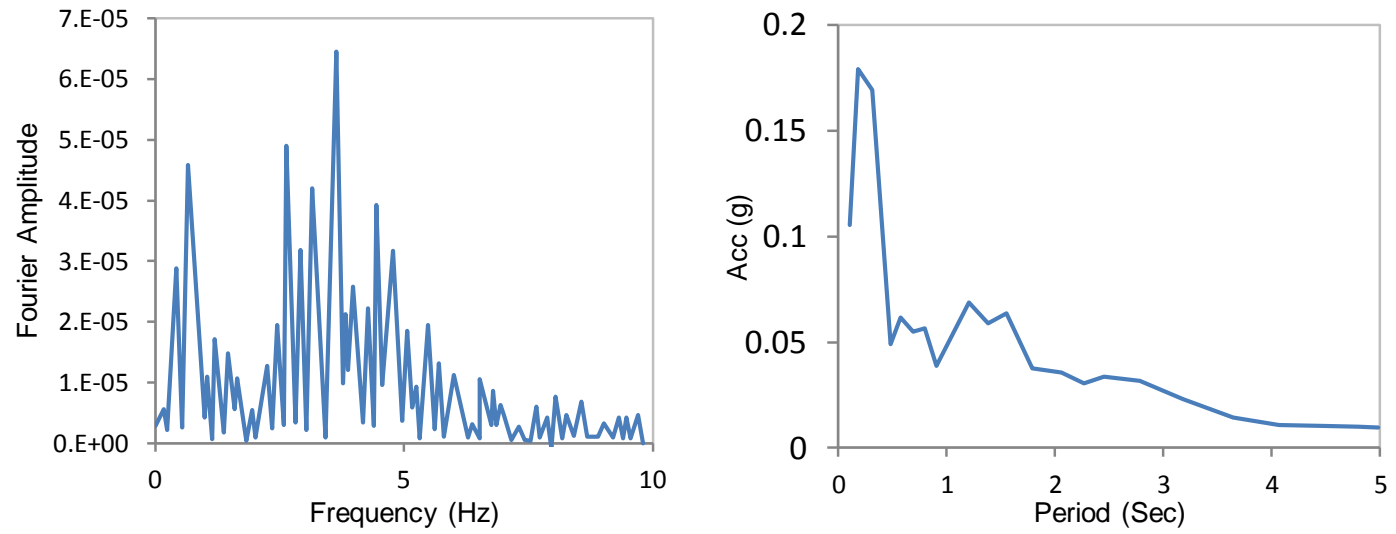

Figure 12: Fourier spectrum and elastic response spectrum for Bangkok site

\section{Case study}

A typical 4 storey commercial frame building located in Bangkok was selected for the case study and details of the building is given in Figure 13. The natural period of the building is 0.8 seconds.

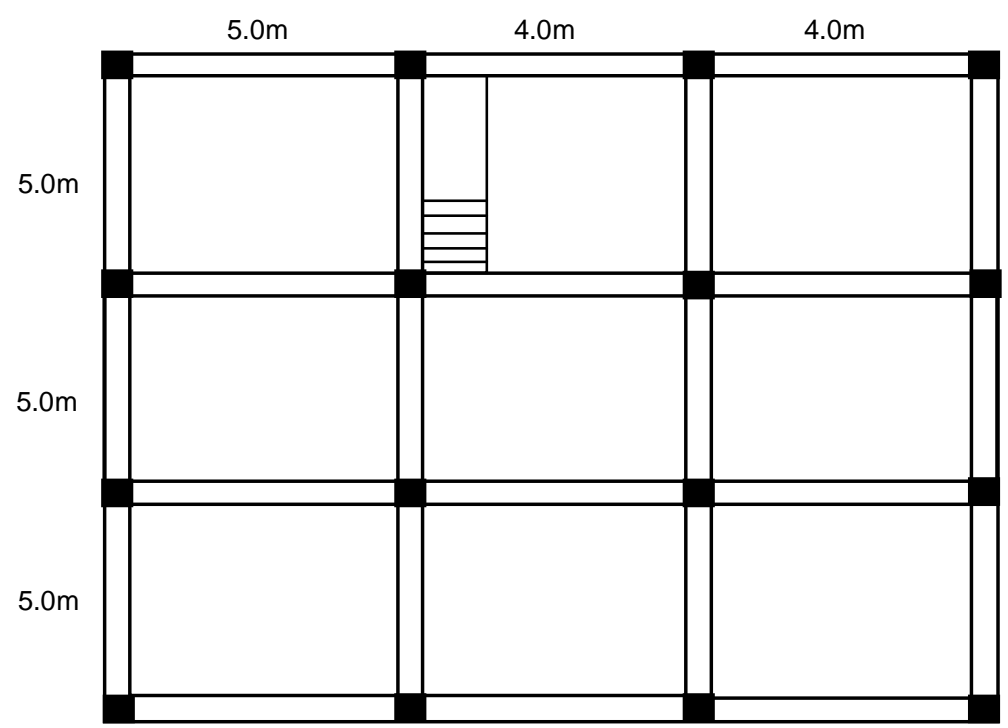

Figure 13: Typical plan for the 4 storey RC frame building 
A series of non-linear seismic analysis was carried out for each pair of $M$ and $R$ given in Table 1 using the computer program "Inelastic Damage Analysis of Reinforced Concrete Frame Shear Wall Structures" (IDRAC) (Park et al. 1987). Beams and columns of the frame were modelled as continuous flexural springs and shear walls were modelled by a combination of flexural and shear deformation springs. The edge columns of the shear wall were modelled separately using one dimensional spring and main transverse beams were modelled using elastic linear and rotational springs. Axial loads generated during earthquakes motion was not considered in this study. The horizontal ground motion was considered and gravity load is assumed to be sufficient to accommodate the dynamic effects of the vertical component.

When a structure responds inelastically, and a close form functional relationship between load effects and loading parameters are available, the statistical mean and standard deviation can be obtained by the approximation in terms of the statistics of the individual load parameters (Ang and Tang 1975). The variability of earthquake loading parameters and structural properties considered in this study includes, ground motion $\left(\mathrm{I}_{0}\right)$, significant ground motion duration $\left(\mathrm{S}_{0}\right)$, damping coefficient $\left(\zeta_{\mathrm{g}}\right)$, predominant frequency $\left(\mathrm{f}_{\mathrm{g}}\right)$, peak ground acceleration $\left(a_{D}\right)$, yield strength of reinforcing steel $\left(f_{y}\right)$, concrete strength $\left(f_{c}\right)$, storey mass (m) and mass proportional damping $\left(\xi_{\mathrm{d}}\right)$. Therefore the random structural response can be written as;

$\mathrm{Q}=\mathrm{f}\left(\mathrm{I}_{0}, \mathrm{~S}_{0}, \zeta_{\mathrm{g}}, \mathrm{f}_{\mathrm{g}}, \mathrm{a}_{\mathrm{D}}, \mathrm{f}_{\mathrm{y}}, \mathrm{f}_{\mathrm{c}}, \mathrm{m}, \xi_{\mathrm{d}}\right)$

Where, response parameter Q was considered as the damage index for this study.

The variabilities of the yield strength of reinforcing steel, concrete strength, structural mass and structural damping was sampled using Latin Hypercube sampling. Each probability distribution of these properties was divided into 32 equal probabilities and matched by Latin Hypercube sampling technique with 32 ground motions. Thus each pair of $\mathrm{M}$ and $\mathrm{R}$, there was 32 ground motion structural models.

The structural damage index for all these models were computed as per Park et al, (1987) and it was noted that damage index is log-normally distributed. Park and Ang (1985) indicated that buildings with damage indices greater than 0.2 showed unacceptable damage. Therefore in this study, damage index greater than 0.2 was selected to be the ultimate limit state criterion. Based on this criterion, damage for the frame building under different earthquake 
intensities and epicentral distances are shown in Table 5. Results show that reasonable damage indices are predicted using the developed attenuation and amplification models for the commercial building.

Table 5: Interpretation of the damage indices for the frame building

\begin{tabular}{|c|c|c|c|}
\hline \multirow{2}{*}{$M$} & \multirow{2}{*}{$\mathrm{R}(\mathrm{km})$} & \multicolumn{2}{|c|}{ 4 Storey building } \\
\cline { 2 - 4 } & 50 & $\mu_{\mathrm{D}}$ & $\mu_{\mathrm{D}+1} \sigma_{\mathrm{D}}$ \\
\hline \multirow{3}{*}{5.5} & 100 & Minor & Minor \\
& 150 & Slight & Minor \\
& 50 & Slight & Minor \\
\hline \multirow{3}{*}{6.0} & 100 & Minor & Moderate \\
& 150 & Minor & Moderate \\
& 50 & Slight & Minor \\
\hline \multirow{3}{*}{6.5} & 100 & Minor & Moderate \\
& 150 & Minor & Moderate \\
& & Minor & Moderate \\
\hline
\end{tabular}

\section{Conclusion}

A probability based method for the calculation of seismic vulnerability for Bangkok was developed in this study. Important characteristics such as peak ground acceleration, $a_{D}$, ground motion intensity, $I_{0}$, frequency content, significant ground duration, $\mathrm{S}_{\mathrm{o}}$, for rock, stiff ground and Bangkok soft soil were developed. Statistical information on the attenuation and amplification models of the peak ground acceleration, 90\% ground motion intensity, significant ground motion duration, predominant frequency and damping coefficient have been established and can be summarised as follows.

- The probability distributions of the peak ground acceleration models for rock, stiff ground and Bangkok soft soil sites are shown to be log normally distributed with the coefficient of variation of $0.69,0.53$ and 0.51 respectively.

- The probability distribution of $90 \%$ ground intensity model, $\mathrm{I}_{\mathrm{o}}$ for rock, stiff firm ground and Bangkok soil sites are log normally distributed with the coefficient of variation of 1.03, 1.35 and 1.17 respectively.

- The probability distributions of the significant ground motion duration, $\mathrm{S}_{\mathrm{o}}$ for rock, stiff firm ground and Bangkok soft soil sites are shown to be log normally distributed with the coefficient of variation of $0.818,0.9531$ and 0.27 respectively 
- The power spectral density function for modeling frequency content of ground motions for Bangkok sites exhibits two peaks of predominant frequency. The first peak is $0.5 \mathrm{~Hz}$ which is the natural frequency of the soft soil. The second peak is the predominant frequency of rock motions.

- Developed attenuation and amplifications model was capable of predicting reasonable damage indices for a typical 4 storey commercial building under seismic conditions in Bangkok. Extension of this work is necessary to examine the applicability of the proposed model for other available building types in Bangkok.

\section{References}

AIT (1981) Results of Laboratory tests on Subsoils of Bangkok and Adjacent Areas vol 2. Asian Istitute of Technology, Thailand

Ang AHS, Tang WH (1975) Probability Concepts in Engineering Planning and Design: vol Volume I. John Wiley \& Sons, Inc, New York

Arango I, Dietrich RJ (1972) Soil and earthquake uncertainties on site response studies. Paper presented at the International Conference on Microzonation for safer construction, Research and application,

Charusiri P, Daorerk V, Muangnoichareon N, Lamjuan A, Kosuwan S (2004) Exploration of active fault in Kanchanaburi, Lampang and Phrae province project. Technical report, Department of Geology. Faculty of Science, Chulalongkorn University.,

Clough RW, Penzien J (1993) Dynamics of structures / Ray W. Clough, Joseph Penzien. New York : McGraw-Hill, c1993. 2nd ed.,

Dobry R, Idriss IM, NG E (1978) Duration Characteristics of Horizontal Components of StrongMotion Earthquake Records Bulletin of the Seismological Society of America 68:1487-1520

Esteva L, Villaverde R (1973) Seismic risk, design spectra and structural reliability. Paper presented at the Proc. 5th World Conference on Earthquake Engineering, Rome,

Esteva L, Villaverde R (1977) Seismic Risk, Design Spectra and Structural Reliability. Paper presented at the Proceedings of the Sixth World Conference on Earthquake Engineering, New Delhi,

Fenton CH, Charusiri P, Wood SH (2003) Recent paleoseismic investigations in northern and western Thailand Anna Geophys 46:957-981

Frankel A (1995) Mapping seismic hazard in the Central and Eastern United States Seismological Research Letters 66:8-21

Gutenberg B, Richter CF (1956) Earthquake Magnitude, Intensity, Energy, and Acceleration Bulletin of the Seismological Society of America 46:105-145

Hinthong C (1995) The study of active faults in Thailand. Paper presented at the Proceedings of the annual technical 1995 conference on the progression and vision of mineral resources development,

Hwan KS (1985) Dynamic Analysis of Ground Motion during Earthquake in Bangkok. Unpublished Degree og Master of Engineering,

Kosuwan S, Hinthong C, Charusiri P (1999) The preliminary use of MapInfo programme to earthquake hazard assessment in Thailand and mainland SE Asia J Geol Ser B 13-14:174-178 
Kuwamura H, Galambos TV (1989) Earthquake load for structural reliability Journal of Structural Engineering 115:1446-1462 doi:10.1061/(ASCE)0733-9445(1989)115:6(1446)

Lai SSP (1982) Statistical Characterisation of Strong Ground Motions using Poewr Spectral Density Function Bulletin of the Seismological Society of America 72:259-274

McKay MD, Beckman RJ, Conover WJ (1979) A Comparison of Three Methods for Selecting Values of Input Variables in the Analysis of Output from a Computer Code. The American Society for Quality Control and The American Statistical Association,

Nutalaya P, Shrestha (1990) Earthquake ground motions and seismic risk in Thailand. Paper presented at the Proc. 1990 Annual Conference Engineering Institute of Thailand, Bangkok,

Ornthammarath T, Warnitchai P, Worakanchana K, Zaman S, Sigbjörnsson R, Lai CG (2011) Probabilistic seismic hazard assessment for Thailand Bulletin of Earthquake Engineering 9:367-394 doi:http://dx.doi.org/10.1007/s10518-010-9197-3

Palasri C (2006) Probabilistic seismic hazard map of Thailand. Chulalongkorn University, Thailand

Park YJ, Ang HS (1985) Seismic damage model for reinforced concrete Journal of structural Engineering, ASCE 111:722-739

Park YJ, Reinhorn AM, Kunnath SK (1987) Inelastic damage analysis of reinforced concrete frame shear wall structure. State University of New York, Buffalo, USA,

Petersen MD, Dewey J, Hartzell S, Mueller C, Harmsen S, Frankel AD, Rukstales K (2004) Probabilistic seismic hazard analysis for Sumatra, Indonesia and across the Southern Malaysian Peninsula Tectonophysics 390:141-158 doi:10.1016/j.tecto.2004.03.026

Sadigh K, Chang CY, Egan JA, Makdisi F, Youngs RR (1997) Attenuation relationships for shallow crustal earthquakes based on California strong motion data. Seismological Research Letters 68:180-189

Samuthsakorn S (1983) Earthquake in Kanjanaburi. Meteorological Department of Thailand, Bangkok, Thailand,

Schnabel PB, Lysmer J, Seed HB (1972) SHAKE: A Computer Program for Earthquake Response Analysis of Horizontally Layered Sites. University of California, Berkeley, Earthquake Engineering Research Center

Seed HB, Idriss IM (1969) Characteristic of rock motions during earthquake Journal of the Soil Mechanics and Foundations Division 95:1199-1218

Seed HB, Idriss IM (1970) Soil moduli and damping factors for dynamic response analysis. University of California, Berkeley, USA, Earthquake Engineering Research Centre

Seed HB, Murarka R, Lysmer J, Idriss IM (1976) Relationships of Maximum Acceleration, Maximum Velocity, Distance from Source, and Local Site Conditions for Moderately Strong Earthquakes Bulletin of the Seismological Society of America 66:1323-1342

Tso WK, Zhu TJ, Heidebrecht AC (1992) Engineering implication of ground motion A/V ratio Soil Dynamics and Earthquake Engineering 11:133-144 doi:10.1016/0267-7261(92)90027-B

Vanmarcke EH, Lai SSP (1980) Strong-motion duration and RMS amplitude of earthquake records Bulletin of the Seismological Society of America 70:1293-1307

Warnitchai P, Lisantono A (1996) Probabilistic seismic risk mapping for Thailand. Paper presented at the 11th world conference on earthquake engineering, Acapulco, June 23-28 


\section{University Library}

\section{- M M N E R VA A gateway to Melbourne's research publications}

Minerva Access is the Institutional Repository of The University of Melbourne

Author/s:

Herath, N;Mendis, P;Zhang, L

Title:

A probabilistic study of ground motion simulation for Bangkok soil

Date:

2017-05-01

Citation:

Herath, N., Mendis, P. \& Zhang, L. (2017). A probabilistic study of ground motion simulation for Bangkok soil. BULLETIN OF EARTHQUAKE ENGINEERING, 15 (5), pp.1925-1943. https://doi.org/10.1007/s10518-016-0058-6.

Persistent Link:

http://hdl.handle.net/11343/283294 